\title{
A NEW DESIGN OF PRECISION RESISTANCE STANDARD
}

\author{
By James L. Thomas
}

ABSTRACT

As a result of investigations of the causes of the slight changes in the resistance of standards of the type developed by Josa, a new type of precision resistance standard has been developed. The coils are wound of bare manganin wire and annealed at a red heat in order to remove the winding strains. They are mounted in double-walled sealed containers which contain no oil or other cooling liquid. A group of new $1 \mathrm{ohm}$ coils, for which data are given, have been remarkably constant in resistance.

CONTENTS

I. Introduction

II. A new method of annealing 295

III. Data on new standards 296

1. One ohm No. $42 \ldots$

2. One ohm No. 36

3. One ohm No. 38

4. One ohm coil, not numbered 298

5. One ohm No. 46

6. One ohm No. 47 299

7. One ohm No. 48 299

8. One ohm No. 49

9. One ohm No. $52 \ldots 300$

IV. Discussion of data. 300

1. Material

2. Annealing 301

3. Stability

4. Temperature coefficient

V. Design of container

VI. Summary _... 304

VII. Acknowledgments 304

\section{INTRODUCTION}

Since 1910 the unit of electrical resistance for this country has been maintained by 1 ohm standards of the type developed by Rosa and described by him in a bulletin of this bureau. ${ }^{1}$ A number of these 1 ohm standards are kept under observation, and it is assumed that the average resistance of the 10 best standards in this group remains constant. The individual standards of this reference group of 10 seldom show changes greater than 3 or 4 parts in 1,000,000 per year with respect to the average. If an unusually large change is shown by one of the standards, it is discarded from the group of 10 and replaced by one which has shown a satisfactory performance in the preceding several years.

The unit of resistance which has been so maintained has probably not changed on the average by more than 1 part in $1,000,000$ per year since 1910, although there are indications that this average yearly change may be increasing. Moreover, the increasing accu- 
racy with which electrical measurements are being made has made it seem desirable to still further increase the stability of standards used for this purpose. With this in mind, experiments were begun in 1928 at this bureau to ascertain the causes of the small changes in the resistance of standards of the sealed type.

While no complete explanation of the changes in resistance has been found, a new design of $1 \mathrm{ohm}$ standard has been developed as a result of these investigations. Several standards of this new type have been under observation for over a year, and their performance to date leads to the expectation that they will prove far superior to those now in use. This increase in stability has apparently resulted from the removal of the winding strains by annealing the resistance coils at a red heat, from the use of a better quality of manganin wire, and from the use of a new design of sealed container.

\section{A NEW METHOD OF ANNEALING ${ }^{2}$}

Coils for the standards designed by Rosa were prepared and baked according to the methods used at the Physikalisch-Technische Reichsanstalt and described by Feussner ${ }^{3}$ and Lindeck. ${ }^{4}$ Silkcovered manganin wire was wound on silk-covered brass tubes, impregnated with shellac varnish, and baked for several hours in air at $140^{\circ} \mathrm{C}$., the maximum temperature to which the silk insulation could safely be subjected. This baking reduced the resistance of the coils, probably as the result of a partial annealing, and increased the stability of their resistance. During the first few weeks after such an annealing, however, there is a rise in resistance of the coils amounting to 0.01 per cent or more in many cases. For this reason the baked coils are generally kept several months before they are used.

Since baking at $140^{\circ} \mathrm{C}$. removed to only a limited extent the strains produced in the wire during manufacture and those resulting from winding, it was decided to try a higher temperature in order to anneal the wire more thoroughly. To do this, several coils of bare manganin wire were wound on mandrels and properly spaced with bare copper wire. They were then placed in a vacuum Arsem furnace and heated to a temperature of $500^{\circ} \mathrm{C}$. or above. This so thoroughly annealed the coils that they held their shapes perfectly upon removal from the mandrels. They were then slipped onto silk-insulated brass tubes of the same diameter as that of the mandrels, tied down and spaced with linen thread, shellacked and baked for an hour at about $80^{\circ} \mathrm{C}$. Several temperatures and times of annealing were tried, the best results being obtained when the furnace temperature was raised slowly to about $550^{\circ} \mathrm{C}$., and the furnace then allowed to cool with the power cut off.

\section{DATA ON NEW STANDARDS}

The following tables show the performance of a number of 1-ohm standards whose coils were annealed at a red heat. They include all coils which have so far been annealed by the method which was decided upon as most satisfactory. The resistances are expressed in

${ }^{2}$ After this paper had been written the attention of the author was called to the fact that Burstall, in 1896, annealed the coils for a resistance box at red heat by passing a current through them. Phil. Mag.,
42, fitth series, p. 210; 1896.

Zeitschr. für Instrumentk., 10, p. 6; 1890.

1 British Association Report, p. 145; 1892. 
terms of the "International Ohm" maintained, as explained above, since 1910 at the National Bureau of Standards by means of wirewound resistance standards. This unit is the so-called Washington unit. $^{5}$ The values of $\alpha$ and $\beta$ listed under the heading of "temperature coefficient" are defined by the equation

$$
R_{t}=R_{25}\left[1+\alpha(t-25)+\beta(t-25)^{2}\right]
$$

'where $R_{t}$ is the resistance at $t^{\circ} \mathrm{C}$. and $R_{25}$ is the resistance at $25^{\circ} \mathrm{C}$.

\section{ONE OHM NO. 42}

Material.-No. $16 \mathrm{AWG}(0.051$ inch $=1.29 \mathrm{~mm})$ manganin wire obtained from the Driver-Harris Co., Harrison, N. J. Chemical analysis of sample taken from same spool: Copper 81.7 per cent, manganese 11.8 per cent, nickel 5.1 per cent, iron 1.4 per cent.

Thermoelectromotive force.-Against copper, in interval $20^{\circ}-30^{\circ} \mathrm{C}$, thermal electromotive force is 1.8 microvolts per ${ }^{\circ} \mathrm{C}$. for the unannealed wire.

Annealing.-Annealed July 14, 1928, in Arsem furnace for 20 minutes at about $600^{\circ} \mathrm{C}$.

Resistance.-

\begin{tabular}{|c|c|c|c|}
\hline Date & $\begin{array}{l}\text { Resistance } \\
\text { at } 25^{\circ} \mathrm{C} \text {. }\end{array}$ & Date & $\begin{array}{l}\text { Resistance } \\
\text { at } 25^{\circ} \mathrm{C} \text {. }\end{array}$ \\
\hline 1928 & \multirow{5}{*}{$\begin{array}{r}0.999928 \\
.999932 \\
.999931 \\
.999930 \\
.999932\end{array}$} & 1928 & \multirow{5}{*}{$\begin{array}{r}0.999931 \\
.999931 \\
.999931\end{array}$} \\
\hline July 17 & & Nov. $30 \ldots$ & \\
\hline Aug. 13 & & Dec. 10 & \\
\hline Aug. 21 & & Dec. $22 \ldots$ & \\
\hline Sept. 1 & & 1929 & \\
\hline Sept. 5 & \multirow{4}{*}{$\begin{array}{r}999931 \\
.999931 \\
.999931 \\
.999930\end{array}$} & Jan. 28 & $\begin{array}{r}.999932 \\
.999932\end{array}$ \\
\hline Sept. 13 & & & \\
\hline Sept. 24 & & Feb. 27 & $\begin{array}{r}.999932 \\
999932\end{array}$ \\
\hline Uct. 4 --- & & Apr. $2 \ldots$ & .999931 \\
\hline Oct. 22 & .999931 & May 8_. & . 999932 \\
\hline Nov. 14 & .999931 & July $22 \ldots$ & .999933 \\
\hline Nov. $2 i$ & .999931 & Oct. 2 & .999931 \\
\hline
\end{tabular}

Temperature coefficient.-For finished coil in the interval $20^{\circ}$ to $30^{\circ}$ C. $\alpha=19.4 \times 10^{-6}, \beta=-0.22 \times 10^{-6}$. For sample of wire from same spool, without annealing, $\alpha=-0.9 \times 10^{-6}, \beta=-0.42 \times 10^{-6}$.

\section{ONE OHM NO. 36}

Material.-No. 14 AWG $(0.064$ inch $=1.63 \mathrm{~mm})$ manganin wire, obtained from the Driver-Harris Co., Harrison, N. J. Chemical analysis of sample taken from same spool: Copper 79.1 per cent, manganese 10.2 per cent, nickel 10.3 per cent, iron 0.4 per cent.

Thermoelectromotive force.-Against copper, in interval $20^{\circ}$ to $30^{\circ} \mathrm{C}$., thermal electromotive force is 4.3 microvolts per ${ }^{\circ} \mathrm{C}$. for unannealed wire.

Annealing.-Arsem furnace was slowly brought up to about $550^{\circ}$ C. and then allowed to cool with pump in operation. Annealed October 1, 1928.

\section{Resistance.-}

8 See Report to the International Committee on Electrical Units and Standards, Jan. 1, 1912, published by this bureau. 


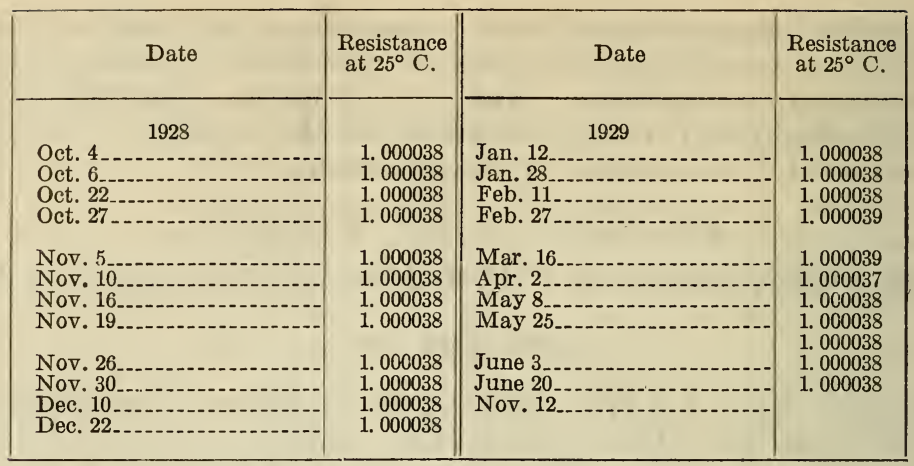

Temperature coefficient.-For the completed coil in the interval $20^{\circ}$ to $30^{\circ}$ C. $\alpha=12.5 \times 10^{-6}, \beta=-0.18 \times 10^{-6}$. For sample of wire taken from same spool and measured without annealing, in the same interval, $\alpha=6.7 \times 10^{-6}, \beta=-0.3 \times 10^{-6}$.

\section{ONE OHM NO. 38}

Material.-Same as for No. 36.

Annealing.-Same as for No. 36. Annealed November 9, 1928. Resistance.-

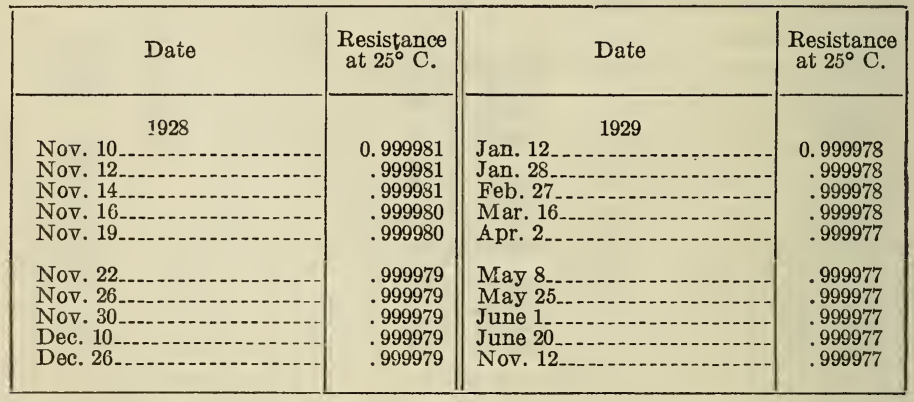

Temperature coefficient.-For completed coil in the interval $20^{\circ}$ to $30^{\circ}$ C. $\alpha=11.6 \times 10^{-6}, \beta=-0.22 \times 10^{-6}$.

\section{ONE-OHM COIL, NOT NUMIBERED}

Material.--Same as for No. 36.

Annealing.- Same as for No. 36. Annealed December 18, 1928. Resisiance.-

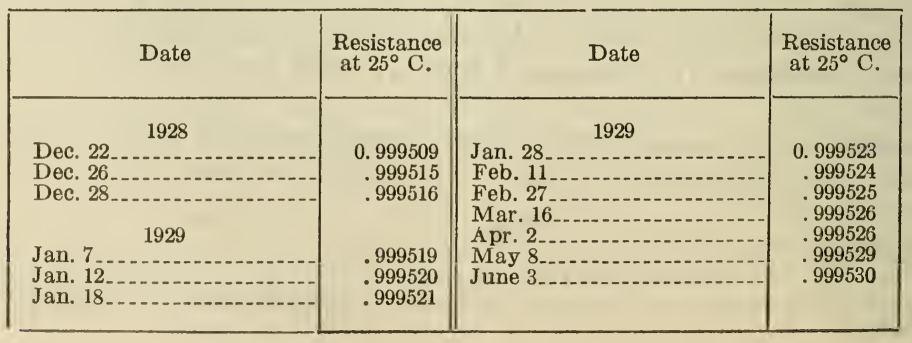


Temperature coefficient.-For completed coil in the interval $20^{\circ}$ to $30^{\circ}$ C. $\alpha=14.6 \times 10^{-6}, \beta=-0.28 \times 10^{-6}$.

Remarks.-This coil was damaged when the copper terminal plates were silver soldered to the ends of the coil. After this soldering there was a fairly large area where the wire appeared to have been blistered. This area was cleaned with emery cloth and the coil was mounted in order to see what effect the overheating would produce. This probably accounts for the instablity of the resistance and for the slightly larger temperature coefficient.

5. ONE OHM NO. 46

Material.-From same spool as No. 36.

Annealing.-Same as for No. 36. Annealed May 17, 1929.

Resistance.-

\begin{tabular}{|c|c|c|c|}
\hline Date & $\begin{array}{l}\text { Resistance } \\
\text { at } 25^{\circ} \mathrm{C} \text {. }\end{array}$ & Date & $\begin{array}{l}\text { Resistance } \\
\text { at } 25^{\circ} \mathrm{C} \text {. }\end{array}$ \\
\hline 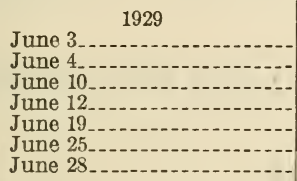 & $\begin{array}{r}0.999499 \\
.999501 \\
.99902 \\
.999501 \\
.99902 \\
.999502 \\
.999503\end{array}$ & 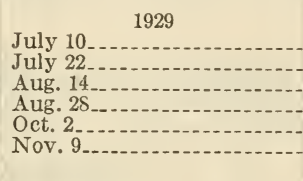 & $\begin{array}{r}0.999503 \\
.999503 \\
.999503 \\
.999503 \\
.999502 \\
.999502\end{array}$ \\
\hline
\end{tabular}

Temperature coefficient.--For completed coil in the interval $20^{\circ}$ to $30^{\circ}$ C. $, \alpha=10.9 \times 10^{-6}, \beta=-0.19 \times 10^{-6}$.

\section{ONE OHM NO. 47}

Material.-From same spool as No. 36.

Annealing.-Same as for No. 36. Annealed May 28, 1929.

Resistance.-.

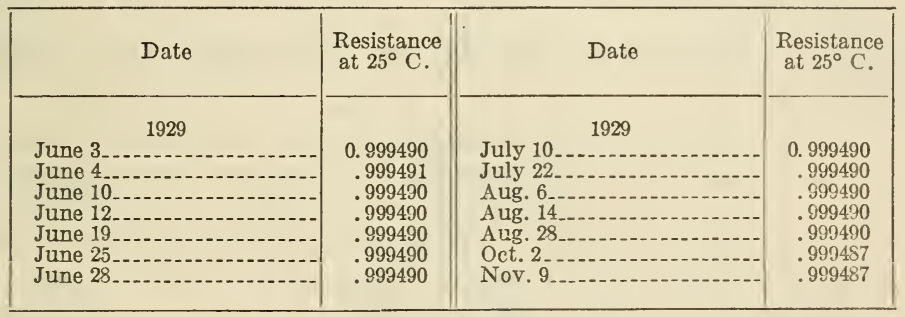

Temperature coefficient.-For completed coil in the interval $20^{\circ}$ to $30^{\circ} \mathrm{C}$. $\alpha=11.7 \times 10^{-6}, \beta=-0.15 \times 10^{-6}$.

\section{ONE OHM NO. 48}

Material.-From same spool as No. 36. Annealing.-Same as for No. 36. Annealed May 22, 1929. Resistance.-

\begin{tabular}{|c|c|c|c|}
\hline Date & $\begin{array}{l}\text { Resistance } \\
\text { at } 25^{\circ} \mathrm{C} \text {. }\end{array}$ & Date & $\begin{array}{l}\text { Resistance } \\
\text { at } 25^{\circ} \mathrm{C} \text {. }\end{array}$ \\
\hline $\begin{array}{l}\text { June } 10 \\
\text { June } 12 \\
\text { June } 19 \\
\text { June } 25 \\
\text { June } 28\end{array}$ & $\begin{array}{r}0.999508 \\
.999509 \\
.999509 \\
.999510 \\
.999510 \\
.999511\end{array}$ & $\begin{array}{l}\text { July } 22 \\
\text { Jug. } \\
\text { Aug. } 629 \\
\text { Aug. 14 } \\
\text { Aug. } 28 \\
\text { Oct. } 2 \\
\text { Nov. } 9\end{array}$ & $\begin{array}{l}.0999511 \\
.999512 \\
.999512 \\
.999512 \\
.999510 \\
.999511\end{array}$ \\
\hline
\end{tabular}


Temperature coefficient.-For completed coil in the interval $20^{\circ}$ to $30^{\circ}$ C., $\alpha=12.7 \times 10^{-6}, \beta=-0.32 \times 10^{-6}$.

\section{ONE OHM NO. 49}

Material.-From same spool as No. 36. Before annealing this coil was plated with a thin coating of gold. Plated June 11, 1929.

Annealing.-Same as for No. 36. Annealed June 19, 1929.

Resistance.-

\begin{tabular}{|c|c|c|c|}
\hline Date & $\begin{array}{l}\text { Resistance } \\
\text { at } 25^{\circ} \mathrm{C} \text {. }\end{array}$ & Date & $\begin{array}{l}\text { Resistance } \\
\text { at } 25^{\circ} \mathrm{C} \text {. }\end{array}$ \\
\hline $\begin{array}{l}\text { June } 24.929 \\
\text { June } 25- \\
\text { June } 28 \\
\text { July } 10 \\
\text { July } 22 \\
\text { July } 29\end{array}$ & $\begin{array}{l}0.999490 \\
.999490 \\
.999491 \\
.999492 \\
.999491 \\
.999491\end{array}$ & $\begin{array}{l}\quad 1929 \\
\text { Aug. } 6 \\
\text { Aug. } 14- \\
\text { Aug. } 28 \\
\text { Oct. } 2 \text {. } \\
\text { Nov. } 9\end{array}$ & $\begin{array}{r}0.999492 \\
.999492 \\
.999492 \\
.999491 \\
.999491\end{array}$ \\
\hline
\end{tabular}

Temperature coefficient.-For completed coil in the interval $20^{\circ}$ to $30^{\circ}$ C., $\alpha=12.4 \times 10^{-6} ; \beta=-0.24 \times 10^{-6}$.

\section{ONE OHM No. 52}

Material.-No. 14 AWG (0.064 inch $=1.63 \mathrm{~mm})$ manganin wire obtained from the Driver-Harris Co., Harrison, N. J., in August, 1929. Chemical analysis of sample taken from same spool: Copper, 82.9, per cent; manganese, 12.6 per cent; nickel, 4.1 per cent; iron less than 0.3 per cent.

Thermoclectromotive force.-Against copper, in the interval $20^{\circ}$ to $30^{\circ} \mathrm{C}$., thermal electromotive force is 1.2 microvolts per ${ }^{\circ} \mathrm{C}$. for the unannealed wire.

Annealing.-Same as for coil No. 36. Annealed August 20, 1929. Resistance.-

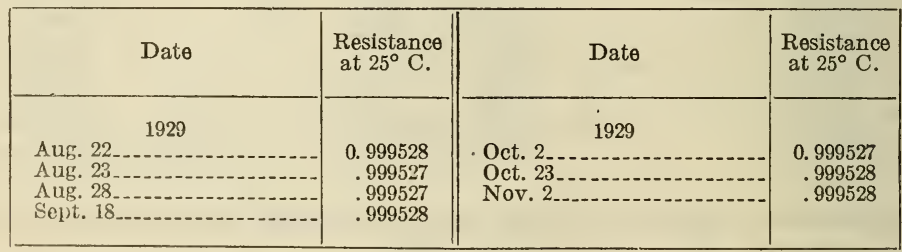

Temperature coefficient.-For completed coil in the interval $20^{\circ}$ to $30^{\circ}$ C., $a=6.1 \times 10^{-6} ; \beta=-0.5 \times 10^{-6}$. For sample of wire taken from same spool, without annealing, $a=-3.3 \times 10^{-6} ; \beta=-0.5 \times 10^{-6}$.

\section{DISCUSSION OF DATA}

\section{MATERIAL}

These $1-0 h m$ standards were made from three lots of wire which differed greatly in composition. For example, No. 36 had about 7 per cent more nickel but 2 per cent less manganese than coil No. 52 . In spite of this wide difference in composition, the coils have all remained very constant in resistance, 'This seems to indicate that 
little improvement in stability can be expected as a result of careful control of the composition of the manganin.

The wire used in making these coils appeared to have been very carefully handled during fabrication, showing no evidence of surface cracks. Before winding, the wire was very carefully polished with a fine grade of emery paper and then cleaned with alcohol, as it is entirely possible that the condition of the surface of the wire has considerable influence upon the stability.

\section{ANNEALING}

The annealing given coil No. 36 was found most satisfactory. When annealed at an appreciably lower temperature the coils would expand upon removal from the mandrels, thus showing that the winding strains had not been thoroughly removed. When annealed for a long time at $550^{\circ} \mathrm{C}$., or at a higher temperature, the coils were less constant in resistance, suggesting an undue amount of surface action.

As yet, no attempt has been made to ascertain the nature of the surface action which takes place during the annealing. 'The atmosphere in the furnace is probably carbon monoxide gas at a pressure of 2 or $3 \mathrm{~mm}$ of mercury. After annealing in this atmosphere, the coils are grayish brown in color. Even coil No. 49, which had previously been gold plated, showed considerable discoloring of the surface as a result of the annealing.

\section{STABILITY}

It is obvious that these new 1 -ohm standards have remained remarkedly constant in resistance, as compared with new coils made according to the usual practice. Some of the standards have shown no appreciable change, while the remainder, except for one damaged in soldering, changed in resistance by 3 or 4 parts in $1,000,000$, generally during the first month, with little or no change thereafter. It is possible that this initial change is due to a slight burning of the manganin wire where terminal plates are silver soldered to the ends. The standards with which these new ones were compared were measured every six months in terms of the reference group of 10. At each measurement they were found to have changed slightly in resistance, and hence it is possible that the new standards would have appeared even more constant in resistance than appears from the data had they been measured each time in terms of the reference group.

Since $1-\mathrm{ohm}$ coils annealed at $550^{\circ} \mathrm{C}$. proved to be very stable in resistance, the same annealing was tried for coils of other values. These, however, have not been very satisfactory, especially the coils of small wire. If the method is to be used, it seems probable that a different heat treatment will be required for each size of wire.

In making international comparisons of resistance standards, considerable uncertainty has been introduced by changes that take place during shipment. Some experiments with the effect of temperature upon the constancy of resistance standards point to heating as a possible cause of this change in resistance. Three of the Rosa type of sealed standards were put in an oven and maintained at $35^{\circ} \mathrm{C}$. for a week, after which the temperature was raised to $45^{\circ} \mathrm{C}$. and the standards maintained at that temperature for an additional week. 
At the end of the two weeks, one standard had decreased in resistance by 9 parts in 1,000,000 while the other two had increased by 5 and 11 parts, respectively. Two of the new standards were given the same treatment and showed no change. Three of the new standards were therefore sent to Europe during the summer of 1929 for measurement in the British and German national laboratories. These were sent in June and received back in November. Measurements before sending and upon their return gave the same values to the nearest part in a million. It should be stated, however, that these standards were carried by hand instead of being shipped by express. For this reason there was no chance of their being subjected to temperatures as high as would be possible if carried in the hold of a steamship. However, since they showed no change when kept at a temperature of $45^{\circ} \mathrm{C}$. for a week, it is not believed that any temperature encountered during shipment would appreciably alter their resistance.

\section{TEMPERATURE COEFFICIENT}

Of the standards for which data are given, seven were made from the same spool of manganin wire. Except for the rejected coil, the spread in the values of $\alpha$ for these standards is about 2 parts in $1,000,000$, the values being five or six millionths higher than for the wire from which the coils were wound. The increase is due primarily to the baking, as the resistance of the copper terminal plates is such as to raise the temperature coefficient by just about 1 part in $1,000,000$. This latter increase could be avoided by using manganin terminal plates. In view of the small spread in the values of $\alpha$ for the completed standards, it appears quite feasable to start with wire having the proper negative value of $\alpha$ and obtain completed standards with extremely small temperature coefficients.

\section{DESIGN OF CONTAINER}

A number of the standards made according to Rosa's design have developed slight leaks around the terminals where they pass through the hard-rubber tops, thus reducing the advantage obtained by sealing the standards. When opened, the oil in these containers was found to be acid, although it is not known whether or not this is due to their becoming unsealed. In order to avoid the chance of the resistance being affected by anything in the oil, the new standards have been mounted in double-walled containers which contain no oil or other cooling liquid. Double-walled containers used at this bureau for a number of years to seal coils for use in bridges have proved quite satisfactory, and they were readily adapted for use as cases for standards.

The containers are made of two coaxial brass tubes differing only slightly in diameter. These tubes are held apart at each end by metal rings, and the space between the tubes is sealed by soldering the rings to the tubes. The inside tube, shown in Figure $1(a)$, is $6 \mathrm{~cm}$ in diameter and a half millimeter thick. One end of this tube is spun outward to form a flange of the same diameter as the inside of the larger tube, which is $7 \mathrm{~cm}$ in diameter and also a half millimeter in thickness. A short piece of thin brass tubing, which telescopes with the latter is spun inward to form a flange and then soldered into the upper end of the 7-cm tube, as shown in Figure $1(b)$. The two 
halves of the container are then assembled and soldered to form the completed container shown in Figure $1(c)$. The walls of the container are very thin; and if tinned in advance, the two parts may be soldered together without unduly heating the coil, which occupies the closed space between the tubes.

The success of this type of container is due to the method of sealing the leads which was devised by Wenner and described in a paper by Waidner, Dickinson, Mueller, and Harper. ${ }^{6}$ The leads are brought through holes drilled through the inner container wall. These holes are covered with copper plates, bent to fit snugly against the container wall. The coil ends are silver soldered to these plates. At the center of the plates are silver-soldered braided copper lead wires, as shown in Figure 2. A layer of silk cloth impregnated with gum shellac is placed between the copper plates and the container wall; the shellac is melted by applying a hot soldering copper to the copper plate and then the plate is pressed down tightly against the container wall, covering the holes, with the flexible lead wires passing through.
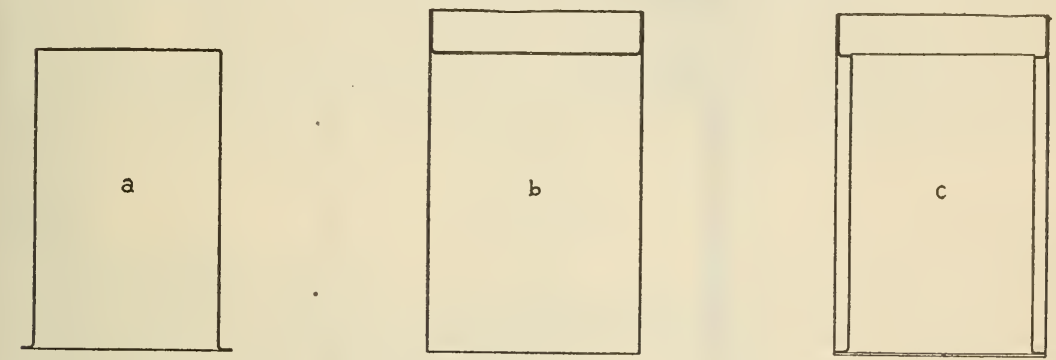

FIGURE 1.-Cross section of container for new type of resistance standards

When the shellac cools and hardens, a tight seal is obtained with good insulation for the leads.

After the coils have been annealed on a 6-cm mandrel, they are cut to the desired length and the copper plates are silver soldered to their ends, care being taken not to heat the wire unnecessarily. 'The coils are then slipped over the silk-covered inner tubes of the containers in such a way as not to make any permanent bends in the wire. After sealing the leads, the coils are pulled down tightly against the container wall, tied, and spaced with linen thread, after which they are shellacked and baked at $80^{\circ} \mathrm{C}$. Final adjustment of the resistance is then made by carefully filing in such a way that no filings get down between the turns of the coil. The filed part is then shellacked and allowed to air dry, or is it again baked at $80^{\circ} \mathrm{C}$. After final adjustment, the containers are assembled and soldered, the leads then being soldered to the proper terminals, which are mounted in a hardrubber or bakelite top. A view of the completed standard is shown in Figure 2. Although no liquid is put in the container the construction is such as to give very effective cooling, especially when kept in a wellstirred oil bath. The standards assume the temperature of the bath much more rapidly than do those of the Rosa type.

\footnotetext{
B B. S. Bull., 11, p. 575; 1915.
} 


\section{SUMIMARY}

1. Precision resistance standards of the type developed by Rosa undergo changes in resistance.

2. By annealing the resistance coils at a red heat, the constancy of 1-ohm resistance coils has apparently been greatly increased, the best results being obtained from coils annealed at about $550^{\circ} \mathrm{C}$.

3. The average change in resistance of $1-\mathrm{ohm}$ coils that have been under observation for as much as six months is slightly over 2 parts

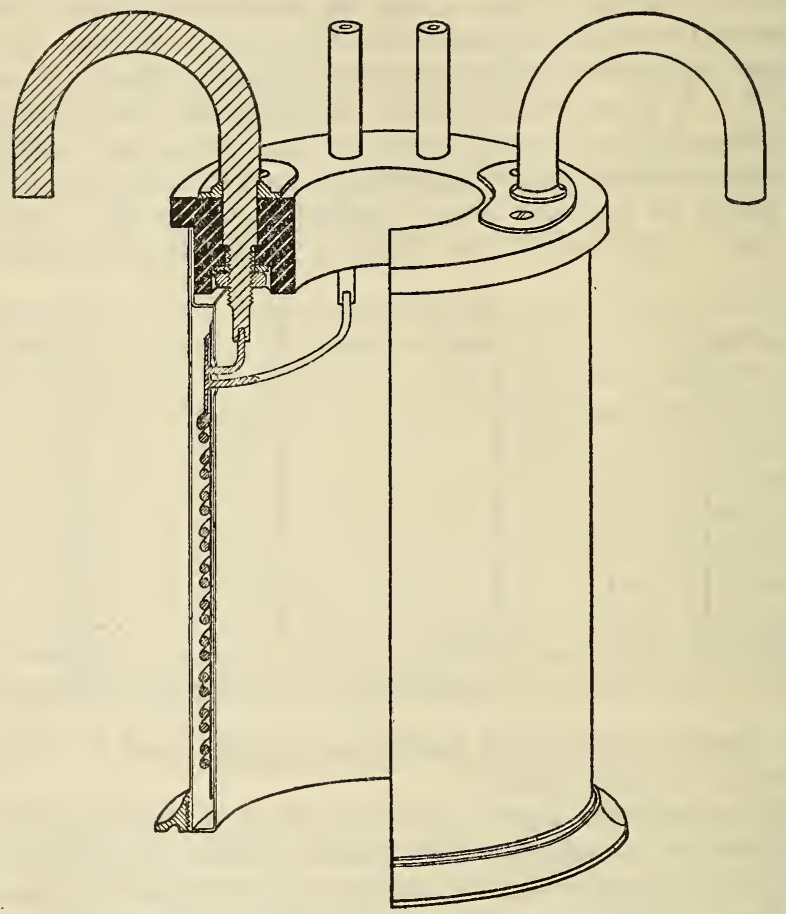

Figure 2.-New type of resistance standard

in $1,000,000$. The greatest part of this change generally takes place in the first month.

4. The data obtained seem to show that the stability is not affected by relatively large differences in the composition of the resistance material.

5. A double-walled sealed container has been designed to be more permanent and afford better protection from surface action than is given by those of the Rosa type.

\section{ACKNOWLEDGMENTS}

Grateful acknowledgement is made to J. A. Scherrer, of the chemistry division, for the chemical analyses of the manganin wire used in the construction of these standards, and to Louis Jordan and W. H. Swanger for assistance in annealing the coils.

Washington, May 5, 1930. 